\title{
Aeromagnetic survey in Kusatsu-Shirane volcano, central Japan, by using an unmanned helicopter
}

\author{
Takao Koyama ${ }^{1 *} \mathbb{D}$, Wataru Kanda², Mitsuru Utsugi ${ }^{3}$, Takayuki Kaneko ${ }^{1}$, Takao Ohminato ${ }^{1}$, Atsushi Watanabe , \\ Hiroshi Tsuji ${ }^{1}$, Taro Nishimoto ${ }^{1}$, Alexey Kuvshinov ${ }^{1,4}$ and Yoshiaki Honda ${ }^{5}$
}

\begin{abstract}
Kusatsu-Shirane volcano is one of the active volcanoes in Japan. Phreatic explosions occurred in Mt. Shirane in 1983 and most recently, in 2018, in Mt. Motoshirane. Information on the subsurface structure is crucial for understanding the activity of volcanoes with well-developed hydrothermal systems where phreatic eruptions occur. Here, we report aeromagnetic surveys conducted at low altitudes using an unmanned helicopter. The survey aimed to obtain magnetic data at a high spatial resolution to map the magnetic anomaly and infer the magnetization intensity distribution in the region immediately after the $2018 \mathrm{Mt}$. Motoshirane eruption. The helicopter used in the survey was YAMAHA FAZER R G2, an autonomously driven model which can fly along a precisely programmed course. The flight height above the ground and a measurement line spacing were set to $\sim 150 \mathrm{~m}$ and $\sim 100 \mathrm{~m}$, respectively, and the total flight distance was $191 \mathrm{~km}$. The measured geomagnetic total intensity was found to vary by $1000 \mathrm{nT}$ peak-to-peak. The estimated magnetization intensity derived from measured data showed a $100 \mathrm{~m}$ thick magnetized surface layer with normal polarity, composed of volcanic deposits of recent activities. Underneath, a reverse-polarity magnetization was found, probably corresponding to the Takai lava flow in the Early Quaternary period ( $1 \mathrm{Ma}$ ) mapped in the region. Our results demonstrate the cost-effectiveness and accuracy of using drone magnetometers for mapping the rugged terrain of volcanoes.
\end{abstract}

Keywords: Kusatsu-Shirane volcano, Aeromagnetic survey, Unmanned helicopter

\section{Introduction}

Kusatsu-Shirane volcano is one of the most active volcanoes located in the central part of Japan. In the area surrounding Kusatsu-Shirane volcano, some Quaternary volcanoes have formed over the Early Quaternary or Tertiary andesitic basement rocks (e.g., Hayakawa and Yui 1989; Terada 2018). At the first stage of the formation history of Kusatsu-Shirane volcano, Matsuozawa lava flow erupted at $\sim 0.5 \mathrm{Ma}$, followed by the Horaguchi lava and Oshi pyroclastic flows (Kaneko et al. 1991).

\footnotetext{
*Correspondence: tkoyama@eri.u-tokyo.ac.jp

${ }^{1}$ Earthquake Research Institute, The University of Tokyo, Yayoi 1-1-1,

Bunkyo-ku, Tokyo 113-0032, Japan

Full list of author information is available at the end of the article
}

Following another eruptive stage, the three main pyroclastic cones, Mt. Shirane, Mt. Ainomine, and Mt. Motoshirane, formed approximately 10,000 years ago and are covered by volcanic deposits with a thickness of a few $100 \mathrm{~m}$ (Hayakawa and Yui 1989). Recent activities were almost only observed in Mt. Shirane, and frequent phreatic explosions occurred every couple of 10 years.

Mt. Ainomine and Mt. Motoshirane have been inactive for 1500 years (Nigorikawa et al. 2016). At the east flank of Mt. Motoshirane, however, there is a large amount of strong acidic hot spring water discharged (as much as 10 ton per minute; Kikawada et al. 2008), implying that a notable widespread hydrothermal system exists beneath Kusatsu-Shirane volcano (e.g., Ohba et al. 2000). 
In active volcanoes with an aquifer, phreatic explosions occur because of the interaction of hot volcanic volatiles with groundwater. Mt. Shirane has experienced such eruptions. Phreatic explosions are usually not preceded by apparent precursory events; thus, it is difficult to predict their occurrence, which consequently leads to damages and casualties. The detection of tiny geophysical and geochemical signals preceding phreatic explosions as well as geological knowledge of the volcano is the key to accurate and timely predictions (Terada 2018).

The current grounded survey was carried out mainly at Mt. Shirane as it was recently active. Takahashi and Fujii (2014) revealed, through repeated ground-based geomagnetic surveys, the long-term thermomagnetic variations corresponding to volcanic activities caused by magnetizing or demagnetizing sources beneath the crater of Mt. Shirane. Tokyo Institute of Technology installed permanent stations of the magnetometer. In 2014, microseismic swarms and geomagnetic changes were detected at the same time in Mt. Shirane. The stations nearest to the Yugama crater showed a rapid decrease in geomagnetic total intensity. This implies that thermal demagnetization occurred just east of the Yugama crater of Mt. Shirane (Hashimoto et al. 2019). These geomagnetic changes may indicate that volcanic activity is getting gradually activated. In contrast, due to a lack of activity, Mt. Motoshirane was considered less likely to erupt than Mt. Shirane and hence, neither geomagnetic nor seismic stations were deployed in the region.

On January 23, 2018, however, there was a phreatic explosion at the Kagamiike-kita pyroclastic cone of Mt. Motoshirane (Ogawa et al. 2018). Volcanic activity on Mt. Motoshirane was low until then and the eruption was unexpected. The estimated mass of volcanic products in this event was not much, being less than 40 thousand tons (Ogawa et al. 2018; Himematsu et al. 2020), but some casualties happened because of lack of preparedness.

Matsunaga et al. (2020) revealed the electrical conductivity structure of Mt. Motoshirane by magnetotelluric surveys. They detected a surface clay-rich alteration layer, $\sim 0.5 \mathrm{~km}$ thick, and a deep and wide conductor which is interpreted to be a hydrothermal fluid reservoir. This reservoir can be a root of volcanic earthquakes occurring beneath Mt. Motoshirane and can also provide volcanic fluid mixed with meteoric water to the hot springs on the eastern flank of Mt. Motoshirane. A resistive body was also detected, which corresponds with basement rocks due to the geological results (Hayakawa and Yui 1989). Tseng et al. (2020) also revealed the electrical conductivity beneath the crater lake, Yugama, of Mt. Shirane, and detected a pathway between Yugama and a deep reservoir. These previous results imply that Kusatsu-Shirane volcano has a variable subsurface structure with some craters, and it is very important to understand it.

We conducted aeromagnetic surveys, with high spatial resolution, to elucidate the Kusatsu-Shirane volcano. Aeromagnetic surveys are used to investigate the inside of the volcanoes to detect thermal anomalies due to demagnetization of subsurface rocks and predict potential eruptive events (e.g., Nakatsuka 1994; Okuma et al. 1994; Finn et al. 2001; Okubo et al. 2005). We used an unmanned helicopter instead of a manually operated one to prevent safety hazards (Kaneko et al. 2011; Koyama et al. 2013; Hashimoto et al. 2014; Ohminato et al. 2017).

In this paper, we have presented an aeromagnetic survey conducted using an unmanned helicopter and the data processing procedure, followed by the estimation of the magnetization intensity distribution to discuss the subsurface structure of Kusatsu-Shirane volcano.

\section{Aeromagnetic survey in Kusatsu-Shirane volcano}

We conducted aeromagnetic surveys of Kusatsu-Shirane volcano, central Japan, in 2018, immediately after the Mt. Motoshirane eruption in January 2018, by using an unmanned helicopter to acquire magnetic field data of high spatial resolution, mitigating potential safety concerns. The unmanned helicopter, YAMAHA FAZER R G2, is driven by an internal combustion engine, and can fly continuously for over $2 \mathrm{~h}$. A common drawback of the usage of internal combustion engines is the lack of combustion efficiency due to decreasing oxygen concentration at high altitude, and the previous model, YAMAHA RMAX G1, did not have the capacity to fly beyond Kusatsu-Shirane volcano the altitude of which is $2171 \mathrm{~m}$ (Morimoto 2017). However, FAZER R G2 is a state-of-the-art vehicle with a four-stroke engine (Kido et al. 2016), and can be operated even at altitudes of $2800 \mathrm{~m}$ (Morimoto 2017). The helicopter provides advantages, such as safety, and also has the ability to fly along a preprogrammed course, owing to which it can fly along the same course repeatedly and can be very useful for repeated surveys to detect temporal changes in geomagnetic fields. The time and position of the helicopter were recorded accurately up to a few tens of centimeters in the horizontal direction and $<1 \mathrm{~m}$ in the vertical direction in a quiet wind condition.

A cesium optical pumping magnetometer (Geometrics G-858 MagMapper Magnetometer) was used to measure the scalar value of geomagnetic total intensity up to $0.1 \mathrm{nT}$ accuracy (Geometrics 2001). Electric power to the magnetometer was supplied by the helicopter generator. Time calibration was performed by the $1 \mathrm{~Hz}$ timestamping tool of a small portable GNSS device, Garmin eTrex H (Garmin 2007) via an RS-232C interface to the magnetometer. Note that positioning data acquired by 
the portable device are generally not very accurate (more than a few meters accuracy) and the positioning data acquired by the helicopter were used instead in the data processing of this study. The time of measurement was adjusted after the survey flights, according to the time of the flight record, containing the precise position information. The console of the magnetometer was fixed to the helicopter body. A magnetic sensor was hung down with a $5.5 \mathrm{~m}$ sensor cable to be installed away from the helicopter body in order to reduce the effect of the vehicle magnetization field. Thus, the position of the magnetic sensor can be assumed to be $5.5 \mathrm{~m}$ beneath the recorded position of the helicopter. The expected total error of measurement is $\sim 10 \mathrm{nT}$ including the effects of a vehicle magnetization field and positioning error due to the swinging of the sensor.

The total weight of magnetometer was $\sim 4 \mathrm{~kg}$, which was much less than the maximum payload of the helicopter (35 kg; Morimoto 2017). Measurements were taken at $10 \mathrm{~Hz}$ sampling. The flight speed was $\sim 10 \mathrm{~m} / \mathrm{s}$, and the typical altitude above the ground was $150 \mathrm{~m}$. A typical survey area measured $\sim 3.5 \mathrm{~km} \times 3.5 \mathrm{~km}$. The survey line spacing was $\sim 100 \mathrm{~m}$, and the total flight distance was $\sim 191 \mathrm{~km}$. Figure 1 shows a plane map of the flight courses, colored by the measurement value of geomagnetic total intensity. The measured geomagnetic total intensity anomaly was as high as $1000 \mathrm{nT}$. A reference station of geomagnetic total intensity was deployed $4 \mathrm{~km}$ away from the survey area to eliminate daily variation in geomagnetic total intensity due to the external geomagnetic field. The same model of the magnetometer Geometrics G-858 MagMapper Magnetometer was used. $10 \mathrm{~Hz}$ sampling was done during flights, which is the same rate as measured by a magnetometer on the helicopter, and $1 \mathrm{~Hz}$ sampling was done in the nighttime to determine a midnight mean value as a baseline.

\section{Data processing and modeling}

The observed geomagnetic total intensity data in the helicopter were decimated to $1 \mathrm{~Hz}$ sampling for precise position and time calibration by the GNSS receiver, and outliers, such as spike noises, were removed. Thereafter, the magnetic field of both the Earth's core and external origins were subtracted from these data to extract the geomagnetic field component only due to volcanic rock origin. The geomagnetic main field of the core origin was assumed to be expressed by the CHAOS-7 geomagnetic field model (Finlay et al. 2020). This main field model has a better time resolution than a common IGRF model published every 5 years, and it can provide the main field data more precisely. The time variation of the external origin was assumed to be identical to that at the reference station. The variation was estimated using the reference field data by subtracting the midnight mean value. Finally, the extracted geomagnetic field data were decimated to provide evenly distributed spatial data, typically with $100 \mathrm{~m}$ spacing.

Using the calculated geomagnetic total intensity anomaly of volcanic origin, the magnetization intensity of Kusatsu-Shirane volcano was estimated, as the orientation of magnetization was assumed to be identical to the direction of the current geomagnetic main field in any position of our targeted area: inclination and declination are $51.0^{\circ}$ downward and $7.9^{\circ}$ westward, respectively.

The details of modeling are described in Appendix. Regarding the target volume $V_{\text {uni, }}$, a much wider area than the survey area, $26 \mathrm{~km} \times 26 \mathrm{~km}$, was considered to avoid artifacts of the edge effect of the model space. Surface topography was referred to as a digital elevation model with a $10 \mathrm{~m}$ horizontal square mesh published by GSI Japan. According to the locations of hypocenters, seismicity can be detected up to $1.5-2.0 \mathrm{~km}$ depth from the surface (e.g., Matsunaga et al. 2020), and brittle-ductile transition may occur at the bottom of the seismic region, at a depth of $1.4 \mathrm{~km}$ (Tseng et al. 2020). Thermal demagnetization of the andesitic rock of Mt. Shirane at $400{ }^{\circ} \mathrm{C}$ may also occur at this depth (Yamazaki et al. 1992); thus, the magnetizing thickness was assumed to be $1500 \mathrm{~m}$ from the surface in this study. A target volume $V_{\text {uni }}$ of $26 \mathrm{~km} \times 26 \mathrm{~km} \times 1.5 \mathrm{~km}$ was assumed to be magnetized, and other areas were assumed not to be magnetized at all. The uniform magnetization intensity $m_{\text {uni }}$ was estimated as $0.97 \mathrm{~A} / \mathrm{m}$. This is close to the results of laboratory measurements of the andesitic rock sampled in Mt. Shirane (Yamazaki et al. 1992). Standard deviation of data misfit between observed data and synthetic data by this uniformly magnetized model was estimated as $134.4 \mathrm{nT}$, which is too large compared to the expected data error $(\sim 10 \mathrm{nT})$.

Regarding the three-dimensional inverse modeling, the target area was assumed to be $19 \mathrm{~km} \times 19 \mathrm{~km}$, still much wider than the survey area, and the magnetizing thickness was again assumed to be $1500 \mathrm{~m}$. A target volume, $V_{\text {ano, }}$ of $19 \mathrm{~km} \times 19 \mathrm{~km} \times 1.5 \mathrm{~km}$, was discretized by blocks with dimensions $250 \mathrm{~m} \times 250 \mathrm{~m}$ in horizontal spacing, and was divided vertically into four layers. The thicknesses of the four layers are 100, 200, 400, and $800 \mathrm{~m}$ from the top layer to the bottom, respectively. Each block was assumed to be uniformly magnetized. Note that each block is not an exact rectangular block, but has fluctuations at the top and bottom due to the topography with a horizontal resolution of $10 \mathrm{~m}$.

Figure 2 shows data misfit between observed geomagnetic total intensity and synthetic data using an optimal model. Standard deviation of data misfit was estimated as $12.7 \mathrm{nT}$, which is close to an expected data error. 


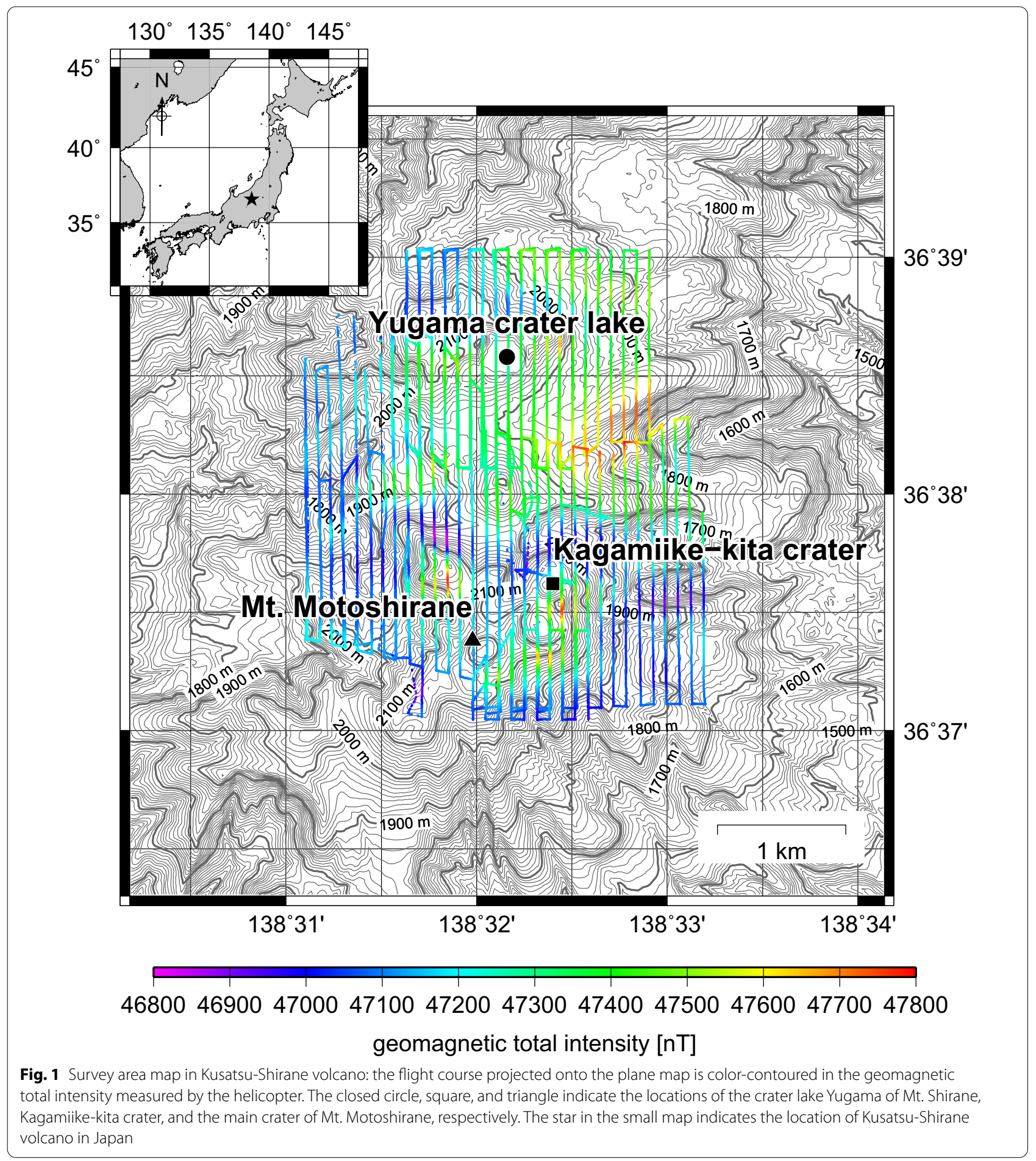

Figure 3 shows the magnetization intensity distribution of each layer of the optimal model. Note that it shows only an area of our survey and surroundings, and does not show all the inverted model space. The model is well inverted in the survey area over which the helicopter took flights. However, the model was not recovered in the area apart from the survey area due to the lack of sensitivity and model resolution. 

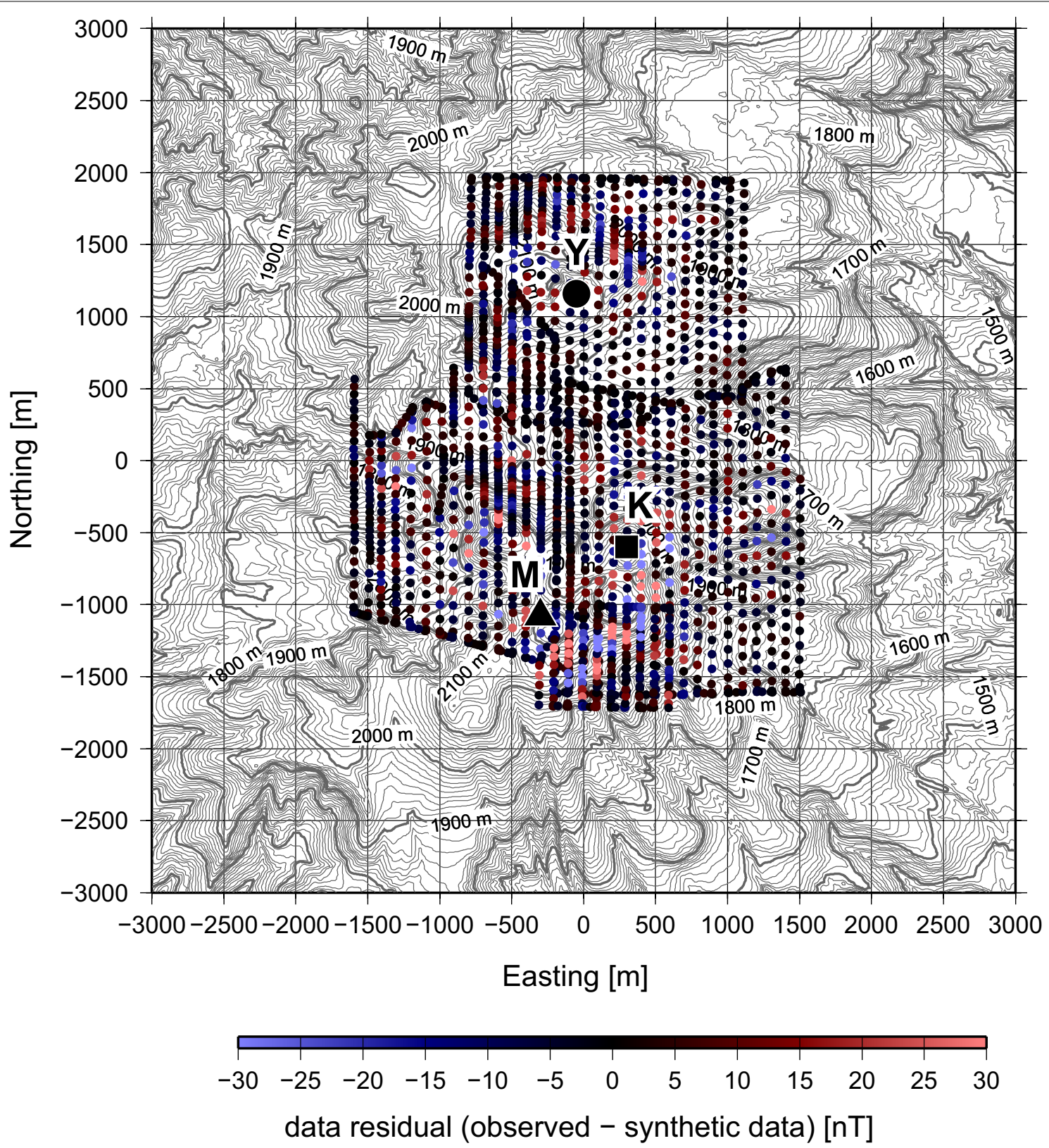

Fig. 2 Data residual between observed value and synthetic value by the optimal magnetization intensity model in Fig. 3. Standard deviation of data misfit is estimated as 12.7 nT. The closed circle with "Y", square with "K", triangle with "M" are the crater lake Yugama of Mt. Shirane, Kagamiike-kita crater, and the main crater of Mt. Motoshirne, respectively

Additional file 1: Figure S1 shows the deviation of model parameters, which is derived from the ABIC minimization shown in Appendix. The first layer is well resolved, and a deviation of model is less than $3.5 \mathrm{~A} / \mathrm{m}$; the second layer is deviated by $1.5-5.8 \mathrm{~A} / \mathrm{m}$. The third is deviated by $6 \mathrm{~A} / \mathrm{m}$ or more. The fourth layer has no resolution, and the deviation is about $20 \mathrm{~A} / \mathrm{m}$. Thus, hereafter, we discuss the magnetization in the first to the third layers.

\section{Discussion}

The top layer in Fig. 3a indicates that the entire surface is magnetized with positive polarity. A surface layer with a thickness of a few $100 \mathrm{~m}$ is composed of volcanic 


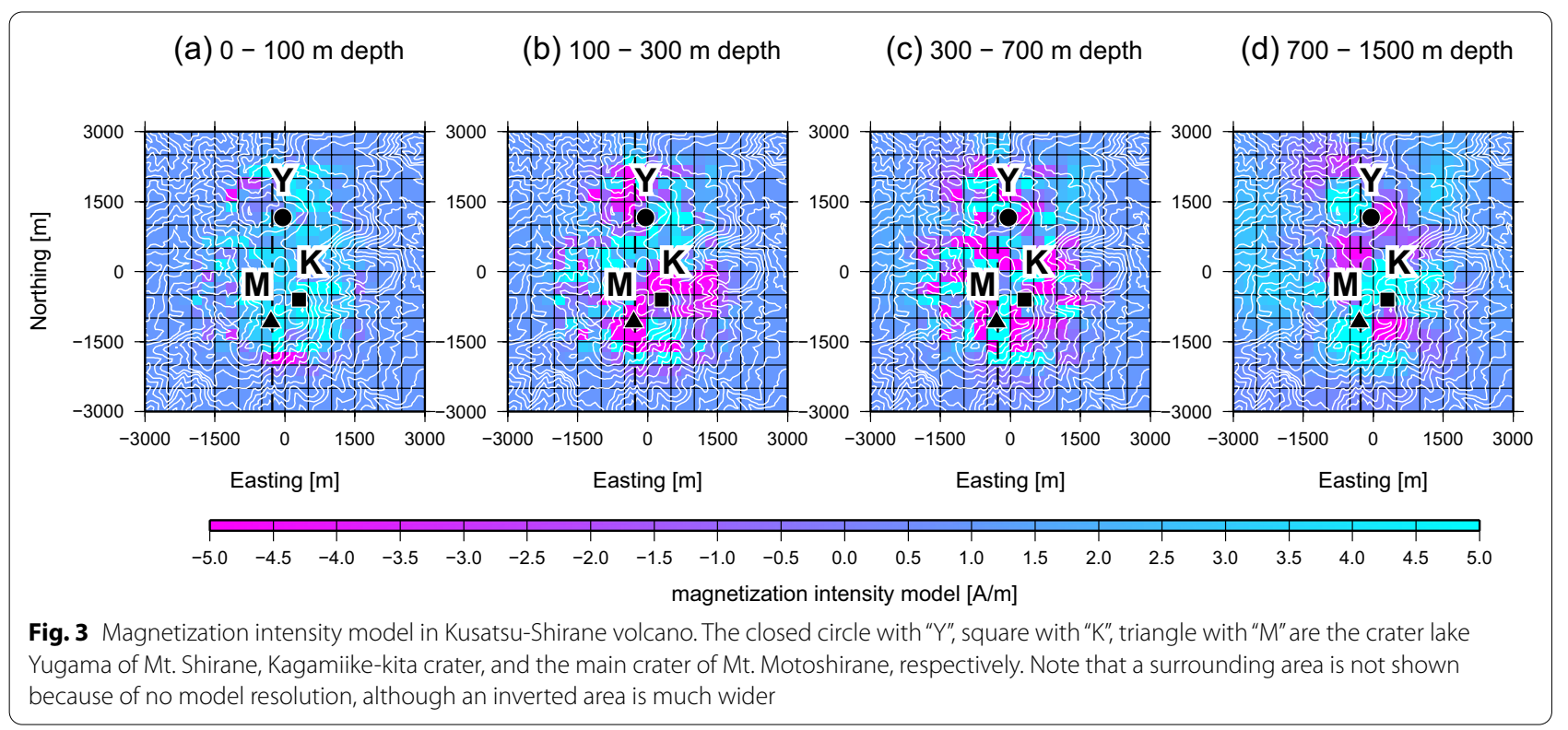

deposits in the middle Quaternary activities ( 0.5 Ma) of Kusatsu-Shirane volcano, such as Matsuozawa lava, Horaguchi lava, Oshi pyroclastic flow, and younger lava flows (Hayakawa and Yui 1989; Kaneko et al. 1991; Uto et al. 2004). Yamazaki et al. (1992) measured the remanent magnetization of pyroxene andesite, sampled close to Yugama Lake, and it exhibited the magnetization intensity as high as $1-2 \mathrm{~A} / \mathrm{m}$, which is consistent with a model in the top layer with weak anomalies.

The second and third layers, shown in Fig. 3b, c down to a depth of $700 \mathrm{~m}$ from the surface, however, indicate negative or almost zero magnetization over a wide area. Akimoto et al. (2002) found that an orientation of the rocks in Yatsugatake, $75 \mathrm{~km}$ south of Kusatsu-Shirane, in about $1 \mathrm{Ma}$ is almost opposite to the orientation of a current main field. Thus, an area with negative magnetization can be interpreted as a reversely magnetized region. Although this might have been caused by overweighting on this layer in the inversion calculation, rocks at these depths may be constituted of basement rock in the early Quaternary, Takai lava. This lava is supposed to be approximately the same age as Omeshi volcano, west of Kusatsu-Shirane volcano (Kaneko et al. 1991). K-Ar dating by Kaneko et al. (1991) shows that the age of Omeshi volcano is $1.10 \pm 0.09 \mathrm{Ma}$. This means that the Takai lava erupted in the early Quaternary which was in Matuyama reversed Chron. Nagai et al. (2015) investigated core data from a drill hole, $3 \mathrm{~km}$ west of Mt. Motoshirane, and found a tuff dating to $1.29 \pm 0.06 \mathrm{Ma}$ at $171.5 \mathrm{~m}$ depth or deeper. Hayakawa and Yui (1989) indicated that there is a long inactive stage, spanning a couple of hundred thousand years between two eruptive stages, and the later eruptive stage may not have used magma, unerupted and solidified in the former eruptive stage. It may have cooled and magnetized lava stayed at this depth after the eruptive stage. Also, it might be highly altered and demagnetized, corresponding to a high conductive region of Takai lava (Matsunaga et al. 2020). Figure 4 shows the North-South vertical profile of the magnetization model through Yugama and Mt. Motoshirane, compared with the electrical resistivity model of Matsunaga et al. (2020). The second and third layers of magnetization model correspond to a conductive layer, which can be altered to clay. Therefore, it is consistent that the second and third layers appear less magnetized and partly reversely magnetized.

The detection of temporal changes in the geomagnetic total intensity by aeromagnetic measurements is very challenging. Figure 5 shows repeatability of data acquisition, that is, deviation of measured data for pairs of sites, which are closer than 5 (in gray color) and 10 (in white color) $\mathrm{m}$ to each other. A typical data error or standard deviation was as small as $10 \mathrm{nT}$ or less in this survey. On the contrary, a temporal change detected by a groundbased survey was a few $\mathrm{nT}$ in the latest measurements (Hashimoto et al. 2019). It seems difficult to detect and is out of the scope of this research. Aeromagnetic survey, however, can measure a wide spatial pattern with high spatial resolution at precisely the same points, which means that spatial stacking to remove the noise can be performed. It may be possible to detect a minor geomagnetic change of volcanic origin with a wide spatial trend 
(a)

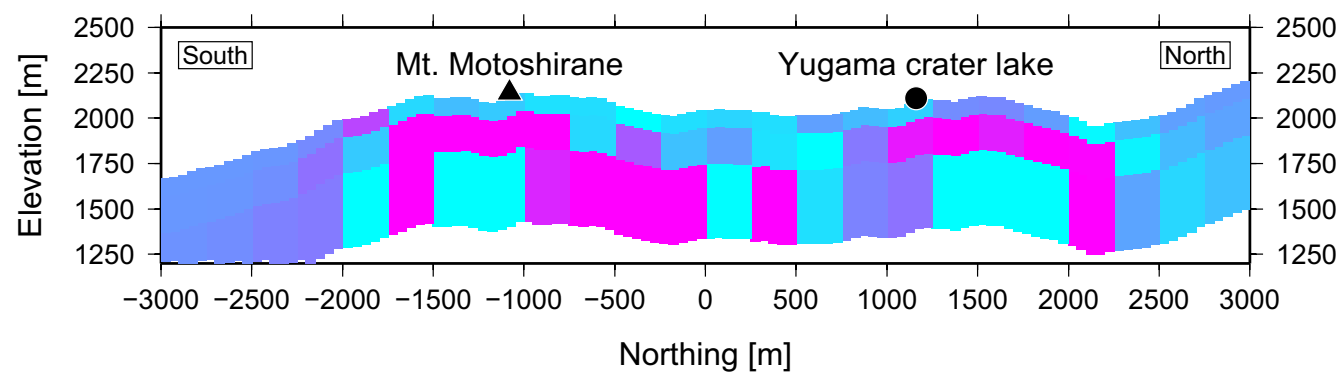

\begin{tabular}{|c|c|c|c|c|c|c|c|c|c|}
\hline-5 & -4 & -3 & -2 & -1 & 0 & 1 & 2 & 3 & 4 \\
\hline
\end{tabular}

(b)

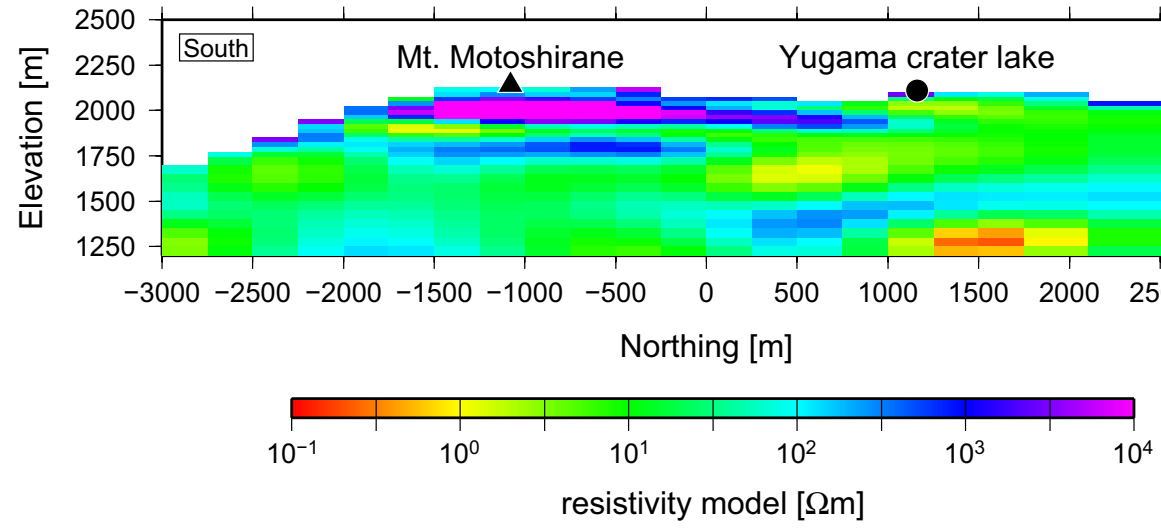

Fig. 4 a Vertical profile of the magnetization intensity model along a dashed line in Fig. 3, through Mt. Motoshirane (closed triangle) and Yugama crater lake of Mt. Shirane (closed circle). $\mathbf{b}$ Vertical profile of the electrical resistivity model by Matsunaga et al. (2020) on the same line of a

even within a noise of $10 \mathrm{nT}$ by repeated airborne measurements in future surveys.

\section{Conclusion}

In this study, highly spatially resolved magnetic field data were acquired from Kusatsu-Shirane volcano, and a geomagnetic field anomaly of approximately $1000 \mathrm{nT}$ was detected using an autonomously driven unmanned helicopter. A three-dimensional magnetization intensity distribution was elucidated by using the measured geomagnetic field data. It shows thin normally magnetized lava at the surface underlain by altered and reversely magnetized lavas. This implies that the main basement lava, Takai lava, can be supposed to have erupted at the time in Matuyama reversed Chron, and have altered later.

Aeromagnetic surveys have shown the potential to elucidate the wide and deep distribution of magnetization. Recently, some studies have reported aeromagnetic surveys using a common drone, which can be easily performed at a low cost (e.g., Utsugi and Hashimoto 2016; Malehmir et al. 2017; Koyama et al. 2019). It can be significantly improved in the near future and can be utilized in volcanic surveys for the detection of temporal changes in the geomagnetic field due to volcanic activity by repeated surveys, combined with ground-based surveys. 


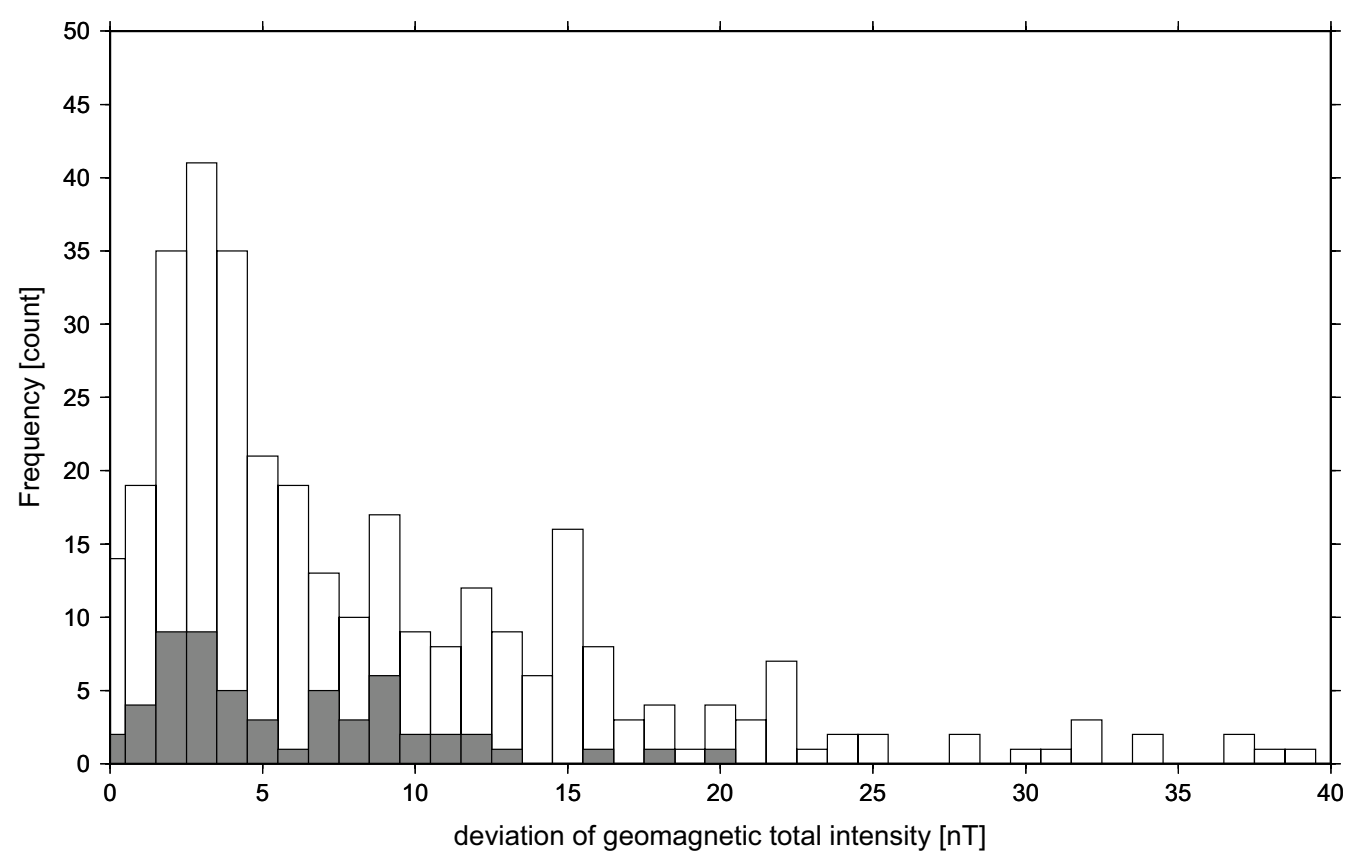

Fig. 5 Deviation of measured geomagnetic total intensity data between a pair of points closer than 5 (in gray color) and 10 (in white color) $\mathrm{m}$ of each other, which shows repeatability of data acquisition by unmanned helicopter

\section{Appendix: Magnetization intensity inversion}

In the first step, the average value of the magnetization intensity, that is, uniform magnetization intensity was estimated in the least squares sense for fitting all the data by removing the trend surface of the geomagnetic field anomaly, minimizing the following objective function, $\Phi_{\text {uni: }}$
The next step is the estimation of three-dimensional anomaly of the magnetization intensity deviating from the average intensity. Various methods of three-dimensional inversion of magnetization have been proposed (e.g., Li and Oldenburg 1996; Nakatsuka and Okuma 2014; Utsugi 2019), and the two-dimensional inver-

$$
\Phi_{\text {uni }}=\sum_{n=1}^{N}\left\{d_{n}\left(x_{n}, y_{n}, z_{n}\right)-m_{\text {uni }}\left(\iiint_{V_{\text {uni }}} K\left(x_{n}, y_{n}, z_{n} ; x^{\prime}, y^{\prime}, z^{\prime}\right) \mathrm{d} x^{\prime} \mathrm{d} y^{\prime} \mathrm{d} z^{\prime}\right)-\left(a_{0}+a_{x} x_{n}+a_{y} y_{n}+a_{z} z_{n}\right)\right\}^{2}
$$

where $d_{n}$ is the $n$th data parameter, which is the measured geomagnetic total intensity subtracted by the core field by the CHAOS- 7 model and the external field variation, $\left(x_{n}, y_{n}, z_{n}\right)$ is a vector of the position of the geomagnetic sensor of the helicopter at the $n$th data parameter, and $N$ is the total number of data parameters. The volume to be uniformly magnetized is given by $V_{\text {uni }}$, and $K\left(x_{n}, y_{n}, z_{n} ; x^{\prime}, y^{\prime}, z^{\prime}\right)$ is a kernel that expressed the geomagnetic total intensity anomaly at position $\left(x_{n}, y_{n}, z_{n}\right)$ generated by a unit magnetizing source at position $\left(x^{\prime}, y^{\prime}, z^{\prime}\right)$. The target uniform magnetization intensity is given by $m_{\mathrm{uni}}$ and $a_{0}+a_{x} x+a_{y} y+a_{z} z$ is an assumed trend surface to be removed, where $a_{0}, a_{x}, a_{y}$ and $a_{z}$ are constant parameters and estimated as well as $m_{\text {uni. The }}$ volume integral in Eq. (1) was derived by following a common formulation for a rectangular prism with magnetization (Bhattacharyya 1964; Kunaratnam 1981). sion method by Koyama et al. (2013) was adapted to the three-dimensional case in this study, which is a commonly used least squares method for fitting the data with model constraints for regularization to minimize the following objective function, $\Phi_{\text {ano }}$.

$$
\begin{aligned}
\Phi_{\text {ano }}= & \sum_{n=1}^{N}\left\{d_{n}^{\prime}\left(x_{n}, y_{n}, z_{n}\right)\right. \\
- & \left.\iiint_{V_{\text {ano }}} K\left(x_{n}, y_{n}, z_{n} ; x^{\prime}, y^{\prime}, z^{\prime}\right) \Delta m\left(x^{\prime}, y^{\prime}, z^{\prime}\right) \mathrm{d} V^{\prime}\right\}^{2} \\
& +\lambda \iiint_{V_{\text {ano }}}\left\{w\left(x^{\prime}, y^{\prime}, z^{\prime}\right) \Delta m\left(x^{\prime}, y^{\prime}, z^{\prime}\right)\right\}^{2} \mathrm{~d} V^{\prime},
\end{aligned}
$$


where $d_{n}^{\prime}$ is the geomagnetic total intensity anomaly of the $n$th data, subtracting components generated by a uniform structure and a trend surface. $V_{\text {ano }}$ is the target volume for three-dimensional inversion. The magnetization intensity anomaly from a uniform model and the weight function on it are represented by $\Delta m\left(x^{\prime}, y^{\prime}, z^{\prime}\right)$ and $w\left(x^{\prime}, y^{\prime}, z^{\prime}\right)$, respectively.

The objective function, $\Phi_{\text {ano }}$, in Eq. (2) can be rewritten using a discretized model anomaly parameter, $\Delta m_{m}$, as follows:

$$
\begin{aligned}
\Phi_{\text {ano }}= & \sum_{n=1}^{N}\left\{d_{n}^{\prime}\left(x_{n}, y_{n}, z_{n}\right)\right. \\
& \left.-\sum_{m=1}^{M} K d V_{m}\left(x_{n}, y_{n}, z_{n}\right) \Delta m_{m}\right\}^{2} \\
& +\lambda \sum_{m=1}^{M}\left\{w_{m} \Delta m_{m}\right\}^{2}
\end{aligned}
$$

where $M$ is the total number of model parameters. $K d V_{m}\left(x_{n}, y_{n}, z_{n}\right)$ is a volume-integrated kernel for the $m$ th model parameter, $\Delta m_{m}$. $w_{m}$ is the weight of the $m$ th model parameter. $\lambda$ is a hyperparameter that balances the data misfit term and model constraint (or roughness) term, which are the first and second terms of the righthand side of Eq. (3).

The model constraint or model roughness term is supposed to minimize the L2 norm of the weighted magnetization intensity anomaly model deviating from an average uniform magnetization intensity, $m_{\text {uni }}$. The weight of the model anomaly $w_{m}$ is assumed to be the square root of the kernel of the model block to the position just above the block at a typical flight height above the ground.

$$
w_{m}=\left|\int_{x_{m}-\frac{\Delta x}{2}}^{x_{m}+\frac{\Delta x}{2}} \mathrm{~d} x^{\prime} \int_{y_{m}-\frac{\Delta y}{2}}^{y_{m}+\frac{\Delta y}{2}} \mathrm{~d} y^{\prime} \int_{z l_{m}\left(x^{\prime}, y^{\prime}\right)}^{z u_{m}\left(x^{\prime}, y^{\prime}\right)} \mathrm{d} z^{\prime} K\left(x_{m}, y_{m}, z_{\mathrm{topo}}+\Delta z ; x^{\prime}, y^{\prime}, z^{\prime}\right)\right|^{\frac{1}{2}},
$$

where $\left(x_{m}, y_{m}\right)$ is the horizontal center position of the $m$ th model block. Note that it is not identical to the weight function of $\mathrm{Li}$ and Oldenburg (2000), but our method avoids overweighting on blocks locating far from the survey area.

The hyperparameter, $\lambda$, to weigh the model constraint was determined by the ABIC minimization concept (e.g., Akaike 1980; Honsho et al. 2012; Koyama et al. 2013). An optimal hyperparameter could be uniquely determined to minimize the $\mathrm{ABIC}$, and the $\mathrm{ABIC}$ minimization concept could select an optimal solution properly, even according to the L-curve criterion by Hansen (1992) (Additional file 2: Figure S2).
According to ABIC, a model covariance matrix $C_{M}$ is derived as follows:

$$
C_{M_{i, j}}=\left[\frac{\left(\sum_{n=1}^{N}\left\{K d V_{i}\left(x_{n}, y_{n}, z_{n}\right) K d V_{j}\left(x_{n}, y_{n}, z_{n}\right)\right\}+\delta_{i j} \lambda w_{i}^{2}\right)}{\Phi_{\mathrm{ano}} / N}\right]^{-1},
$$

where $C_{M_{i, j}}$ is an element $(i, j)$ of the matrix $C_{M} . \delta_{i j}$ is the Kronecker delta.

Thus, a square root of each diagonal element, $\left(C_{M_{m, m}}\right)^{1 / 2}$, can be supposed to simply represent a deviation of the $m$ th model parameter, $\Delta m_{m}$.

\section{Abbreviations}

Ma: Million years ago; RS-232C: Recommended Standard 232 version C; GNSS: Global Navigation Satellite System; IGRF: The International Geomagnetic Reference Field; GSI Japan: The Geospatial Information Authority of Japan; ABIC: Akaike's Bayesian information criterion.

\section{Supplementary Information}

The online version contains supplementary material available at https://doi. org/10.1186/s40623-021-01466-5.

Additional file 1: Figure S1. Deviation of model parameters of magnetization intensity model in Fig. 3, which is represented by a square root of each diagonal element of the estimated model covariance matrix by the $\mathrm{ABIC}$ minimization.

Additional file 2: Figure S2. (a) ABIC with a hyperparameter $\lambda$ dependency. A closed circle is a minimum point of ABIC. (b) Data misfit and model roughness with a hyperparameter $\lambda$ dependency. A closed circle corresponds to an optimal $\lambda$ minimizing $A B I C$ in (a).

\section{Acknowledgements}

A staff of the UMS Business Development Section, YAMAHA Motor Co., Ltd. operated the unmanned helicopter YAMAHA FAZER R G2 in entire surveys. Mr. Yasuo Matsunaga kindly shared the electrical conductivity model of Kusatsu-Shirane with us. The Editor and two anonymous reviewers gave useful comments to improve our manuscript. The Kusatsu town office, the Agatsuma District Forest Office, and the Manza Park Rangers Office granted approvals for the field surveys documented in this study. A digital elevation model with $10 \mathrm{~m}$ horizontal resolution was provided by GSI Japan. Figures in this paper were created partly using Generic Mapping Tools (Wessel et al. 2013).

\section{Authors' contributions}

TKo and MU contributed to data acquisition and data analysis. WK contributed to planning, preparing and organizing of the survey as well as data acquisition. TKa, TO, AW, HT, TN, AK, and YH contributed to support data acquisition and safe flight of the unmanned helicopter. All authors read and approved the final manuscript.

\section{Funding}

This work was supported by JSPS KAKENHI Grant-in-Aid for Special Purposes Number 17K20141, supported by the Ministry of Education, Culture, Sports, Science and Technology (MEXT) of Japan, under The Second Earthquake and Volcano Hazards Observation and Research Program (Earthquake and Volcano Hazard Reduction Research), and supported by the short-term visiting program of the International Research Promotion Office, Earthquake Research Institute, The University of Tokyo. 


\section{Availability of data and materials}

Geomagnetic field data with positioning data of the helicopter as well as the geomagnetic field data at a reference site are available from the corresponding author upon reasonable request.

\section{Declarations}

Ethics approval and consent to participate

Not applicable.

\section{Consent for publication}

Not applicable.

\section{Competing interests}

The authors declare that they have no competing interests.

\section{Author details}

'Earthquake Research Institute, The University of Tokyo, Yayoi 1-1-1, Bunkyo-ku, Tokyo 113-0032, Japan. ${ }^{2}$ Volcanic Fluid Research Center, Tokyo Institute of Technology, Ookayama 2-12-2, Meguro-ku, Tokyo 152-8551, Japan. ${ }^{3}$ Aso Volcanological Laboratory, Institute for Geothermal Sciences, Kyoto University, Kawayou 5280-1, Minami-Aso, Aso, Kumamoto 869-1404, Japan. ${ }^{4}$ Institute of Geophysics, ETH Zürich, Sonneggstrasse 5, 8092 Zürich, Switzerland. ${ }^{5}$ Center for Environmental Remote Sensing, Chiba University, 1-33, Yayoi-cho, Inage-ku, Chiba 268-8522 Chiba-city, Japan.

Received: 31 December 2020 Accepted: 21 June 2021

Published online: 06 July 2021

\section{References}

Akaike H (1980) Likelihood and the Bayes procedure. Trabajos De Estadistica Y De Investigacion Operativa 31:143-166. https://doi.org/10.1007/BF028 88350

Akimoto T, Furuta T, Kawachi S (2002) Paleomagnetic properties of the Yatsugatake volcanic chain, Central Japan. Bull Volcanol Soc Jpn Ser 2(47):435-448. https://doi.org/10.18940/kazan.47.5_435 (in Japanese with English abstract)

Bhattacharyya BK (1964) Magnetic anomalies due to prism-shaped bodies with arbitrary polarization. Geophysics 29:517-531. https://doi.org/10. 1190/1.1439386

Finlay CC, Kloss C, Olsen N, Hammer M, Toeffner-Clausen L, Grayver A, Kuvshinov A (2020) The CHAOS-7 geomagnetic field model and observed changes in the South Atlantic Anomaly. Earth Planets Space 72:156. https://doi.org/10.1186/s40623-020-01252-9

Finn AC, Sisson T, Deszcz-Pan M (2001) Aerogeophysical measurements of collapse-prone hydrothermally altered zones at Mount Rainier volcano. Nature 409:600-603. https://doi.org/10.1038/35054533

Garmin (2007) GARMIN eTrex H personal navigator owner's manual, 1-26. https://static.garmincdn.com/pumac/eTrexH_OwnersManual.pdf. Accessed 3 June 2021

Geometrics (2001) G-858 Magmapper operation manual, 1-106. https:// geometrics.com/wp-content/uploads/2018/10/858Manual_D2.pdf. Accessed 3 June 2021

Hansen PC (1992) Analysis of discrete ill-posed problems by means of the L-curve. SIAM Rev 34(4):561-580. https://doi.org/10.1137/1034115

Hashimoto T, Koyama T, Kaneko T, Ohminato T, Yanagisawa T, Yoshimoto M, Suzuki E (2014) Aeromagnetic survey using an unmanned autonomous helicopter over Tarumae volcano, northern Japan. Explor Geophys 45:37-42. https://doi.org/10.1071/EG12087

Hashimoto T, Utsugi M, Ohkura T, Kanda W, Terada A, Miura S, Iguchi M (2019) On the source characteristics of demagnetization and ground deformation associated with non-magmatic activity. Bull Volcanol Soc Japan 64(2):103-119. https://doi.org/10.18940/kazan.64.2_103 (in Japanese with English abstract)

Hayakawa Y, Yui M (1989) Eruptive history of the Kusatsu Shirane volcano. Quat Res 28(1):1-17. https://doi.org/10.4116/jaqua.28.1 (in Japanese with English abstract)
Himematsu Y, Ozawa T, Aoki Y (2020) Coeruptive and posteruptive crustal deformation associated with the 2018 Kusatsu-Shirane phreatic eruption based on PALSAR-2 time series analysis. Earth Planets Space 72:116. https://doi.org/10.1186/s40623-020-01247-6

Honsho C, Ura T, Tamaki K (2012) The inversion of deep-sea magnetic anomalies using Akaike's Bayesian information criterion. J Geophys Res 117:B01105. https://doi.org/10.1029/2011JB008611

Kaneko T, Shimizu S, Itaya T (1991) K-Ar ages of the quaternary volcanoes in the Shin-etsu highland area, central Japan, and their formation history. Bull Earthq Res Inst Univ Tokyo 66:299-332 (in Japanese with English abstract)

Kaneko T, Koyama T, Yasuda A, Takeo M, Yanagisawa T, Kajiwara K, Honda Y (2011) Low-altitude remote sensing of volcanoes using an unmanned autonomous helicopter: an example of aeromagnetic observation at IzuOshima volcano. Jpn Int J Remote Sens 32(5):1491-1504. https://doi.org/ 10.1080/01431160903559770

Kido T, Ohnishi S, Hirajo D, Kinoshita K, Hayashi T (2016) FAZER R: industrialuse unmanned helicopter with large $32 \mathrm{~L}$ agricultural chemical payload. Yamaha Motor Technical Review, Yamaha Co. Ltd. 52:78-82. https:// global.yamaha-motor.com/jp/design_technology/technical/produ ct/pdf/browse/52ss10.pdf. Accessed 3 June 2021 (in Japanese with English abstract)

Kikawada Y, Kawai S, Shimada K, Oi T (2008) Arsenic originating in Kusatsu hot springs, Gunma, Japan, and arsenic pollution status of Kusatsu rivers. J Disaster Res 3(4):261-269. https://doi.org/10.20965/jdr.2008.p0261

Koyama T, Kaneko T, Ohminato T, Yanagisawa T, Watanabe A, Takeo M (2013) An aeromagnetic survey of Shinmoe-dake volcano, Kirishima, Japan, after the 2011 eruption using an unmanned autonomous helicopter. Earth Planets Space 65:657-666. https://doi.org/10.5047/eps.2013.03.005

Koyama T, Kaneko T, Ohminato T, Watanabe A, Honda Y (2019) Aeromagnetic survey by drone in Iwoyama, Kirishima volcano. In: Abstract of SGEPSS fall meeting 2019, Kumamoto, 23-27 Oct 2019. http://www.sgepss.org/ sgepss/sookai/146/html/program/pdf/R003/R003-P04.pdf. Accessed 3 June 2021 (in Japanese with English abstract)

Kunaratnam K (1981) Simplified expressions for the magnetic anomalies due to vertical rectangular prisms. Geophys Prospect 29:883-890. https://doi. org/10.1111/j.1365-2478.1981.tb01032.x

Li Y, Oldenburg DW (1996) 3-D inversion of magnetic data. Geophysics 61(2):394-408. https://doi.org/10.1190/1.1443968

LiY, Oldenburg DW (2000) Joint inversion of surface and three-component borehole magnetic data. Geophysics 65(2):540-552. https://doi.org/10. 1190/1.1444749

Malehmir A, Dynesius L, Paulusson K, Johansson H, Bastani M, Wedmark M, Marsden P (2017) The potential of rotary-wing UAV-based magnetic surveys for mineral exploration: a case study from central Sweden. Lead Edge 36(7):552-557. https://doi.org/10.1190/tle36070552.1

Matsunaga Y, Kanda W, Takakura S, Koyama T, Saito Z, Seki K, Suzuki A, Kishita T, Kinoshita Y, Ogawa Y (2020) Magmatic hydrothermal system inferred from the resistivity structure of Kusatsu-Shirane volcano. J Volcanol Geotherm Res 390:106742. https://doi.org/10.1016/j.jvolgeores.2019.106742

Morimoto T (2017) Introduction to the satellite-based long-distance, programmable-navigation operation of the FAZER R G2. Yamaha Motor Technical Review, Yamaha Co. Ltd. 53:9-13. https://global.yamaha-motor. com/jp/design_technology/technical/presentation/pdf/browse/53gs02. pdf. Accessed 3 June 2021 (in Japanese with English abstract)

Nagai M, Ueki K, Mizuno Y, Tanaka Y, Inui M, Nogami K, Tanada T (2015) Stratigraphy and radiometric ages of volcanic rocks from the drill hole of the Hoshimata observation station of Kusatu-Shiranesan volcano, Central Japan. In: Abstract of Volcanological Society of Japan 2015 fall meeting, Toyama, 27 Sep-2 Oct 2015. https://www.jstage.jst.go.jp/article/vsj/ 2015/0/2015_113/_pdf/-char/ja. Accessed 3 June 2021 (in Japanese)

Nakatsuka T (1994) Aeromagnetic anomalies over the area of Unzendake volcano. J Geomag Geoelectr 46:529-540. https://doi.org/10.5636/jgg. 46.529

Nakatsuka T, Okuma S (2014) Aeromagnetic 3D subsurface imaging with effective source volume minimization and its application to data from the Otoge cauldron, Shitara, Central Japan. Explor Geophys 45:16-23. https:// doi.org/10.1071/EG13022 
Nigorikawa A, Ishizaki Y, Kametani N, Yoshimoto M, Terada A, Ueki K, Nakamura K (2016) Holocene eruptive history of the Motoshirane Pyroclastic Cone Group, Kusatsu-Shirane volcano. In: Abstract of Japan geoscience union meeting 2016, Makuhari, Chiba, 22-26 May 2016. https:/confit.atlas.jp/ guide/event/jpgu2016/subject/SVC48-11/detail. Accessed 3 June 2021

Ogawa Y, Aoyama H, Yamamoto M, Tsutsui T, Terada A, Ohkura T, Kanda W, Koyama T, Kaneko T, Ohminato T, Ishizaki Y, Yoshimoto M, Ishimine Y, Nogami K, Mori T, Kikawada Y, Kataoka K, Matsumoto T, Kamiisi I, Yamaguchi S, Ito Y, Tsunematsu K (2018) Comprehensive survey of 2018 Kusatsu-Shirane Eruption. In: Proc. Symp. on the natural disaster sciences, 55:25-30 (in Japanese)

Ohba T, Hirabayashi J, Nogami K (2000) D/H and ${ }^{18} \mathrm{O} /{ }^{16} \mathrm{O}$ ratios in the crater lake at Kusatsu-Shirane volcano, Japan. J Volcanol Geotherm Res 97:329-346. https://doi.org/10.1016/S0377-0273(99)00169-9

Ohminato T, Kaneko T, Koyama T, Watanabe A, Kanda W, Tameguri T, Kazahaya $R$ (2017) Observations using an unmanned aerial vehicle in an area in danger of volcanic eruptions at Kuchinoerabu-jima volcano, southern Kyushu. Jpn J Nat Disaster Sci 38(1):85-104. https://doi.org/10.2328/jnds. 38.85

Okubo A, Tanaka Y, Utsugi M, Kitada N, Shimizu H, Matsushima T (2005) Magnetization intensity mapping on Unzen volcano, Japan, determined from high-resolution, low-altitude helicopter-borne aeromagnetic survey. Earth Planets Space 57:743-753. https://doi.org/10.1186/BF03351853

Okuma S, Makino M, Nakatsuka T (1994) Magnetization intensity mapping in and around Izu-Oshima volcano, Japan. J Geomag Geoelectr 46:541-556. https://doi.org/10.5636/jgg.46.541

Takahashi K, Fujii I (2014) Long-term thermal activity revealed by magnetic measurements at Kusatsu-Shirane volcano, Japan. J Volcanol Geotherm Res 285:180-194. https://doi.org/10.1016/j.jvolgeores.2014.08.014

Terada A (2018) Kusatsu-Shirane volcano as a site of phreatic eruptions. Jour Geol Soc Japan 124(4):251-270. https://doi.org/10.5575/geosoc.2017. 0060 (in Japanese with English abstract)
Tseng KH, Ogawa Y, Nurhasan TSB, Ujihara N, Honkura Y, Terada A, Usui Y, Kanda W (2020) Anatomy of active volcanic edifice at the Kusatsu-Shirane volcano, Japan, by magnetotellurics: hydrothermal implications for volcanic unrests. Earth Planets Space 72:161. https://doi.org/10.1186/ s40623-020-01283-2

Uto K, Kurihara A, Hirabayashi J (2004) Core descriptions of seismological observation wells around Shirane cone, Kusatsu Shirane volcano. Report of 4th joint observation of Kusatsu-Shirane volcano 59-68. http://www. ksvo.titech.ac.jp/jpn/kusatsu-2003-shuchu-report/08-Uto.pdf. Accessed 3 June 2021 (in Japanese)

Utsugi M (2019) 3-D inversion of magnetic data based on the L1-L2 norm regularization. Earth Planets Space 71:73. https://doi.org/10.1186/ s40623-019-1052-4

Utsugi M, Hashimoto T (2016) Development of the aeromagnetic survey system using drone multicopter. In: Abstract of SGEPSS fall meeting 2016, Fukuoka, 19-23 Nov 2016. http://www.sgepss.org/sgepss/sookai/140/ html/program/pdf/R003/R003-P11.pdf. Accessed 3 June 2021

Wessel P, Smith WHF, Scharroo R, Luis J, Wobbe F (2013) Generic mapping tools: improved version released. EOS Trans AGU 94(45):409-410. https:// doi.org/10.1002/2013EO450001

Yamazaki A, Churei M, Tsunomura S, Nakajima S (1992) Analysis of the variation of geomagnetic total force at the Kusatsu-Shirane volcano: the remarkable changes in the geomagnetic total force in 1990 and the estimated thermal demagnetization model. Memoirs of the Kakioka Magnetic Observatory 24(2):53-66. https://www.kakioka-jma.go.jp/publ/journal_ DB/pdf_files/technical_report_of_KMO_sup_03_02.pdf. Accessed 3 June 2021 (English translation, original in Japanese)

\section{Publisher's Note}

Springer Nature remains neutral with regard to jurisdictional claims in published maps and institutional affiliations.

\section{Submit your manuscript to a SpringerOpen ${ }^{\circ}$ journal and benefit from:}

- Convenient online submission

- Rigorous peer review

- Open access: articles freely available online

- High visibility within the field

- Retaining the copyright to your article

Submit your next manuscript at $\boldsymbol{\nabla}$ springeropen.com 